\title{
La afectación de los derechos y acciones sociales como bienes familiares. Finalidad y alcance del Art. 146 del Código Civil
}

\author{
María Graciela Brantt Zumaran* \\ Álvaro Vidal Olivares**
}

\begin{abstract}
RESUMEN
El presente trabajo aborda los problemas que origina la posibilidad, prevista por el artículo 146 del Código Civil, de afectar como bienes familiares los derechos y acciones que los cónyuges tengan en una sociedad propietaria del inmueble que sirva de residencia principal de la familia. Las preguntas que se plantean en este trabajo son, por un lado, ¿en quéclase de sociedades procede tal afectación?; y por otro, ¿ a qué actos que inciden en el inmueble mencionado aplica la restricción establecida por la norma? La respuesta a estas interrogantes reclama examinar la finalidad general de los bienes familiares, y aquella que inspira la norma en particular.
\end{abstract}

Bienes familiares - afectación de derechos y acciones sociales - desafectación

$$
\begin{gathered}
\text { Affectation of rights and shares as family goods. } \\
\text { Purpose and scope }
\end{gathered}
$$

\begin{abstract}
This paper addresses the problems caused by the possibility provided by Article 146 of the Civil Code, as household assets affect the rights and actions which the spouses have in a company owning the property that serves as principal family residence. The questions raised in this work are, firstly, what kind of societies such involvement comes?; and secondly, what acts affecting the property mentioned applies the restriction established by the provision? The answer to these questions demands examine the overall aim of family property, and that which inspires the particular provision.
\end{abstract}

Affectation as family goods - rights and shares - alienation of rights and shares

* Doctora en Derecho, Pontificia Universidad Católica de Valparaíso. Profesora de Derecho Civil, Pontificia Universidad Católica de Valparaíso. Correo electrónico: maría.brantt@ucv.cl

** Doctor en Derecho, Universidad Autónoma de Madrid. Profesor de Derecho Civil, Pontificia Universidad Católica de Valparaíso. Correo electrónico: alvaro.vidal@ucv.cl

Artículo recibido el 24 de noviembre de 2015 y aceptado para su publicación el 1 de marzo de 2017. 


\section{INTRODUCCIÓN}

$\mathrm{E}$ 1 presente trabajo tiene por objeto develar el alcance del artículo 146 del Código Civil, que permite la afectación como bienes familiares de derechos y acciones sociales de los cónyuges en sociedades propietarias del inmueble que sirva de residencia principal a la familia. Entendemos que la definición de dicho alcance -fundamental para su aplicación en el terreno práctico- requiere, junto con examinar el tenor de la norma y su historia legislativa, precisar tanto la finalidad general de los bienes familiares como el fundamento que explica el citado artículo 146 y su particular finalidad. Solo a partir de estas consideraciones es posible entender el sentido y alcance de la norma y resolver acerca de la procedencia de su aplicación al caso concreto, en especial, para dar solución a dos problemas que pueden plantearse con ocasión de esta afectación.

Para la consecución de este objeto del trabajo, primeramente ofreceremos un caso para ilustrar el problema y las interrogantes que la aplicación de la regla legal plantea en el terreno práctico. Al responder tales interrogantes, volveremos sobre él a objeto de mostrar las consecuencias que podrían seguirse de una errada aplicación del precepto en estudio en lo que concierne a las cuestiones planteadas.

\section{EL CASO}

La mujer otorga escritura pública por la que declara como bien familiar las acciones de que es titular el marido -las que corresponden al 25\% del capital- en la sociedad propietaria del inmueble, que según expresa el referido instrumento, sirve de residencia principal de la familia.

Ambos contrajeron matrimonio el 2008 bajo el régimen de sociedad conyugal, unión de la que nacieron dos hijos, de cuatro y dos años, respectivamente. Los dos, a su vez, tienen matrimonios anteriores disueltos, en el caso de la mujer con dos hijos menores; $y$, en el del marido, con tres mayores y estudiantes universitarios.

Todos ellos viven, o han vivido, en el inmueble de propiedad de la sociedad -cuyo giro es el de las inversiones en diversos ámbitos-, que fue adquirido por esta antes del primer matrimonio del marido. A partir de su adquisición sirvió como residencia del marido con su primera mujer e hijos; y después solo con estos últimos y, finalmente con su segunda pareja, los hijos de esta y los comunes de ambos.

Al momento de la afectación como bien familiar de las acciones de titularidad del marido en la sociedad, había ocurrido el quiebre matrimonial, no obstante se mantuvo la convivencia en el referido inmueble de los cónyuges y todos sus hijos. Sin embargo, después de la ruptura, es común que la mujer se traslade durante el día junto con sus hijos propios y los comunes a un departamento de que es propietaria exclusiva por haberlo adquirido según el artículo 150 del Código Civil, e incluso en algunas ocasiones pernocta en él.

Este caso plantea las siguientes interrogantes, cuyas respuestas constituyen el objeto del presente trabajo: ¿Procede, bajo estas circunstancias, la aplicación del artículo 146 
del Código Civil, manteniéndose la afectación de las acciones como bien familiar? De ser procedente ¿Cuál sería el alcance de tal afectación? y ¿Qué actos quedarían sujetos a la voluntad del cónyuge no propietario? ¿Puede el cónyuge socio, con éxito, intentar la desafectación de las acciones, por ser improcedente su declaración como bien familiar?

Para resolver estas interrogantes es preciso develar primeramente la finalidad general de los bienes familiares como mecanismo de protección de la familia y, en particular, de la regla especial del artículo 146 del Código Civil, que extiende su ámbito de aplicación alcanzando bienes que, estrictamente, no pertenecen en forma directa al cónyuge, sino por intermedio de una sociedad. Para la definición de esta última finalidad es preciso estudiar el citado precepto, definiendo su sentido y alcance, incluidos los efectos que prevé. Ello permitirá esclarecer respecto de su correcta aplicación y las consecuencias que se podrían seguir de una errónea afectación. El trabajo termina con un cuerpo de conclusiones.

\section{CUESTIÓN PREVIA: LA FINALIDAD DE LA AFECTACIÓN DE LOS BIENES FAMILIARES}

El estatuto de los bienes familiares fue incorporado a nuestra legislación en 1994, por la Ley No 19.335 , que prevé como régimen económico matrimonial, de acceso convencional, el de la participación en los gananciales, con gestión separada y modalidad crediticia a su término. En un principio, de la historia del establecimiento de la ley y teniendo en cuenta sus antecedentes, se infiere que los bienes familiares estaban destinados a operar en conjunto con el referido régimen para paliar los inconvenientes que representaba la administración separada de los cónyuges, atendido que inicialmente la participación en los gananciales se pensaba establecer con carácter supletorio ${ }^{1}$. Por esta razón, en un primer momento se sostuvo que los bienes familiares constituían una manifestación de la protección del cónyuge más débil, en este caso, el no propietario de la vivienda familiar, lo que les daba una naturaleza patrimonial, al ser su finalidad proteger a ese cónyuge mediante la co-gestión del bien declarado familiar, limitando así la libertad de disposición del propietario ${ }^{2}$.

1 Así lo destaca Corral, H., Bienes familiares y participación en los gananciales: la reforma de la Ley $N^{o} 19.335$, de 1994, a las relaciones personales y al régimen económico del matrimonio, Editorial Jurídica de Chile, Santiago, 2007, p. 51.

${ }^{2} \mathrm{Al}$ respecto, es admisible recordar que la incorporación de la participación en los gananciales como régimen legal y de los bienes familiares a nuestro derecho encuentra su primer antecedente en una propuesta del profesor Barros Bourie, quien en la presentación de su proyecto expresa que los bienes familiares constituyen una garantía mínima para el cónyuge patrimonialmente más débil. Barros, E., "Proyecto para introducir en Chile la participación en los gananciales como régimen de bienes normal de matrimonio", en Merino, F. (coord.) Familia y Persona, Editorial Jurídica de Chile, Santiago, 1991, pp. 128 y 130. En este sentido entiende también la figura Rosso, al expresar que los bienes familiares aseguran el cumplimiento de las cargas de familia o del matrimonio, específicamente la de contenido patrimonial correspondiente a la habitación, y que por ello son una suerte de medida precautoria a favor del cónyuge no propietario respecto del inmueble que cumple la función de residencia principal de la familia. Agrega, además, que se trata de una institución establecida a favor de los cónyuges. Si bien expresa que debía tratarse de una figura destinada a proteger a la familia, la 
Sin embargo, al no prosperar la idea de la función supletoria del régimen de participación, quedando este como convencional, los bienes familiares pasan a ser de común aplicación, cualquiera sea el régimen de bienes imperante entre los cónyuges, tomando otra naturaleza, al dejar de constituir un mecanismo protector del cónyuge más débil. Así, los bienes familiares pasan a ser un medio de protección de la familia, asegurando la continuidad de la residencia existente durante el matrimonio; se evita, de este modo, que en casos de ruptura conyugal y disgregación se produzca un perjuicio para el grupo familiar más allá de lo netamente patrimonial. Se persigue evitar que tras el fracaso marital, la familia quede expuesta a abandonar o perder su lugar de residencia en el que, hasta ese instante, se desenvuelve. Como afirma Corral $^{3}$, esta institución cumple una función familiar directa, a saber, permitir y favorecer la convivencia de la familia. Y añade, enfáticamente, que ella no persigue proteger intereses individuales de ninguno de los cónyuges (el no propietario) sino el de la familia ${ }^{4}$. En el mismo sentido se expresa Ramos Pazos, quien asevera que los bienes familiares "persigue (n) asegurar a la familia un hogar físico donde sus integrantes puedan desarrollar la vida con normalidad” y que "pretende evitar que las disputas patrimoniales entre los cónyuges concluyan con el desarraigo de la residencia habitual de la familia"s.

Así, se pierde la idea de identificar a los bienes familiares con un régimen patrimonial primario ${ }^{6}$ y prevalece, imponiéndose, no solo en la historia de la ley y en la doctrina, sino también en la jurisprudencia ${ }^{7}$, el carácter esencialmente protector del

regulación va más en la línea de favorecer exclusivamente a los cónyuges, y especialmente a la mujer, lo que en su opinión se explicaría por el origen de la Ley $\mathrm{N}^{\circ} 19.335$, en cuanto a su finalidad de promover el principio de igualdad ante la ley en relación con aquella, expresada en el Mensaje del ejecutivo. Rosso, G. F., Régimen Jurídico de los Bienes Familiares, Metropolitana Ediciones, Santiago, 1998, pp. 56-59 y 69-71.

${ }^{3}$ Corral, H., cit., pp. 53-55. El autor expresa que los bienes tienen tal calidad porque la ley les reconoce una función esencial con la vida cotidiana de la familia, y ello es lo que explica su protección especial.

${ }^{4}$ Así se ha fallado también por la Corte de Apelaciones de Santiago, en sentencia de 24 de marzo de 1998, en que expresa que la acción contenida en la demanda para la declaración de bien familiar debe llevar “implícita la condición de que con tal declaración se beneficiará no solo al cónyuge no peticionario, sino también a los hijos que viven en el inmueble y que están conviviendo con su padre o madre. Es una acción de beneficio común y no para provecho individual de alguno de los cónyuges y para su propio y especial beneficio", Revista de Derecho y Jurisprudencia, tomo 95, n 1,1998 , pp. 26 y ss. Y en idéntico sentido: Corte de Apelaciones de Concepción, de 23 de marzo de 2007, rol 4379-2005, en Leyes \& Sentencias: Revista de legislación y jurisprudencia, número 37, Puntolex, Santiago, 2007, p. 82.

En la doctrina nacional, Frigerio destaca esta idea también cuando expresa que las normas de los bienes familiares "se fundan en el interés del grupo familiar". El autor muestra que es la familia y no el cónyuge no propietario el destinatario de la protección conferida por los bienes familiares. Frigerio, C., Regímenes matrimoniales, Editorial Jurídica Conosur, Santiago, 1995, p. 148.

${ }^{5}$ Ramos, R., Derecho de Familia, tomo I, Editorial Jurídica de Chile, Santiago, 2010, p. 359.

${ }^{6}$ Que era la idea que inspiraba a Barros, E., cit., pp. 127 y ss. La mirada estaba dada fundamentalmente desde lo patrimonial y hacia la desprotección que desde esa perspectiva enfrentaba el cónyuge no propietario de la residencia familiar.

${ }^{7}$ Nuestros tribunales reiteradamente se han pronunciado en el sentido de que la finalidad es proteger a la familia y resguardar su normal desenvolvimiento y estabilidad. Así, entre otras: Corte de Apelaciones de Concepción, de 23 de marzo de 2007, rol 4379-2005, en que afirma que la institución tiene como principal fundamento: "asegurar a la familia un hogar físico estable donde sus integrantes puedan desarrollar su vida 
interés familiar: su estabilidad y la continuidad de su lugar de residencia. En los casos de ruptura lo que termina es el matrimonio, no así la familia y ella debe ser objeto de protección, siendo este un medio orientado a tal fin. En el propio mensaje que acompañó la indicación sustitutiva enviada por el ejecutivo al tramitarse el proyecto de ley, se expresa que mediante los bienes familiares, y cualquiera sea el régimen que medie entre los cónyuges, "habrá un ámbito patrimonial en que se expresará, en protección de la familia, la comunidad de vida y de intereses que significa el matrimonio" 8 . A lo anterior se suma la intervención, en la discusión en el Congreso, de la entonces ministra Alvear, quien expresa que se trata de "una institución de orden público vinculada a la protección de la familia, en su conjunto, por sobre el interés individual de cada uno de los miembros que la componen"'.

Lo expresado interesa también porque conduce a descartar que estemos ante una institución establecida en beneficio del cónyuge no propietario, lo que por consiguiente lleva a rechazar categóricamente cualquier posibilidad o intento de obtención de un provecho personal o individual de su parte con la afectación. Ello importaría un abuso de los bienes familiares, al alejarse completamente de su finalidad. Se trata de un límite fundamental a la procedencia de la institución, y que se explica, precisamente, por los fines que persigue.

Por esta razón, podemos afirmar que el carácter patrimonial de los bienes familiares es un mero instrumento al que acude el legislador en miras a la consecución de un fin superior: la protección del interés familiar ${ }^{10}$. Así, y no de otra forma, se explican las limitaciones impuestas al cónyuge propietario en el artículo 142 del Código Civil en lo que refiere a la enajenación o gravamen del bien familiar. De lo que se trata es de evitar que aquel, dentro del natural conflicto familiar asociado a la ruptura, disponga de tal

con normalidad"; Corte de Apelaciones de San Miguel, 09/08/2011, identificador LP CL/JUR/6369/2011, disponible en www.legalpublishing3.cl, en que se expresó: "la institución de los bienes familiares, incorporada a nuestra legislación con la dictación de la Ley $\mathrm{N}^{\circ} 19.335$, tiene por finalidad principal amparar el hogar de la familia", y agrega luego: "corresponde poner acento en que el referido instituto encuentra su principal fundamento en la intención de asegurar a la familia matrimonial un lugar donde los integrantes de la misma puedan vivir y desarrollarse". También la Corte Suprema, en sentencia de 21/09/2009, rol: 5275-2009; identificador LP CL/JUR/1194/2009, disponible en www.legalpublishing3.cl, afirma: "Que la institución de los bienes familiares, incorporada a nuestra legislación por la Ley $\mathrm{N}^{\circ} 19.335$, tiene por finalidad principal amparar el hogar de la familia”.

${ }^{8}$ Mensaje indicación sustitutiva, en Historia del establecimiento de la Ley $N^{0} 19.335$, p. 26, disponible en www.bcn.cl

${ }^{9}$ Discusión en la Cámara de Diputados, Legislatura 325, Sesión 52, 10 de marzo de 1993, en Historia del establecimiento de la Ley $N^{\circ} 19.335$, p. 79, disponible en www.bcn.cl

A lo largo de todo el proceso de tramitación de la ley, y en reiteradas ocasiones, se destacó la finalidad protectora de la familia de la institución de los bienes familiares. Así se observa, por ejemplo, en las páginas 76, 82, 108 y 415 de la Historia del establecimiento de la Ley $N^{\circ} 19.335$, disponible en www.bcn.cl

${ }^{10}$ Rechazando claramente el carácter patrimonial de la institución se expresa la Corte de Apelaciones de Concepción, en sentencia de 31/03/2008, identificador LP CL/JUR/7526/2008, disponible en www. legalpublishing3.cl, cuando afirma: "La institución tiene por finalidad principal amparar el hogar familiar, o sea, la protección o interés de la familia, en su calidad de tal y no en su aspecto patrimonial" (lo destacado es nuestro). 
bien, al margen del cónyuge no propietario, provocando un desarraigo y una inestabilidad no deseada por el legislador.

El fin de la norma, al establecer tales limitaciones, no es el propio de los regímenes patrimoniales - generar una suerte de cogestión en miras a la protección de un patrimonio común- sino el de asegurar por intermedio de ellas la residencia y el normal desenvolvimiento de la vida familiar a pesar de la ruptura ${ }^{11}$. Lo patrimonial es meramente accesorio e instrumental para la consecución de este fin.

De este modo, los bienes familiares carecen de una naturaleza patrimonial como el que poseen los regímenes económicos de la sociedad conyugal, la separación de bienes y la participación en los gananciales.

Si quisiera asignársele un sentido a la calificación de "régimen primario" que se le ha dado por algunos, debiésemos entender que con ella se quiere significar que esta institución de protección familiar es compatible con cualquiera de los regímenes patrimoniales en estrictu sensu ${ }^{12}$.

Lo expresado queda demostrado desde que la protección conferida por los bienes familiares no está reducida en forma exclusiva a las limitaciones de administración y disposición a que queda sometido el cónyuge propietario; por consiguiente, según lo previsto por el legislador, la sola declaración de un inmueble como bien familiar no constituye título suficiente para su uso y goce ${ }^{13}$. Estos solo se obtienen y aseguran en la medida que tenga lugar la constitución de los derechos reales previstos por el artículo 147 del Código Civil. Y tales derechos constituyen, en efecto, una segunda manifestación de la protección que persigue conceder esta institución a la familia, y que expresa su finalidad: asegurar la estabilidad de la residencia familiar a pesar de la crisis de los cónyuges. Si bien, por tratarse de derechos reales, tienen un innegable contenido patrimonial, es evidente que, al igual que sucede con las limitaciones a las facultades del cónyuge propietario, están destinados -como hemos expresado-a reforzar esa protección mediante el aseguramiento del uso y goce efectivo del inmueble que sirve de residencia

11 Reconoce también esta finalidad protectora de la familia Schmidt, quien afirma que los bienes familiares obedecen a "la necesidad de garantizar un hogar físico estable para que la familia se desenvuelva normalmente, permitiendo a sus integrantes cumplir con sus roles y funciones", p. 47, agregando luego que "la beneficiaria de los bienes familiares es la familia", Schmidt, C., Nuevo régimen matrimonial. Ley 19335 analizada y comentada, Jurídica Conosur, Santiago, 1995, p. 55.

${ }^{12}$ En este sentido, conviene considerar lo señalado por Corral en cuanto a qué se entiende por régimen matrimonial primario: "el estatuto básico, imperativo e inderogable que se aplica a todos los matrimonios, con independencia del régimen patrimonial que los rija en concreto". Corral, H., cit., p. 53. Si se lo entiende en tal forma, no hay dificultad en calificar a los bienes familiares como parte del régimen primario del matrimonio, que quedaría compuesto además por los derechos y deberes constitutivos de los efectos personales del matrimonio, en tanto se trata también de una regulación común, aplicable a todos los matrimonios.

${ }^{13}$ Hübner destaca este aspecto cuando afirma que la declaración de bien familiar "no afecta el dominio, ni el derecho de goce, y los frutos de los bienes seguirán accediendo a sus dueños, restringiéndose la facultad para realizar actos de disposición en que la gestión tendrá que ser compartida”. Hübner, A. M., Los bienes familiares en la legislación chilena. Problemas y atisbos de solución, en Cuadernos de Extensión Universidad de los Andes, número 2, Santiago, 1998, p. 123. 
principal de la familia y los muebles que lo guarnecen. Así, la constitución de estos derechos reales guarda perfecta concordancia con la finalidad de la institución.

Lo mismo es posible señalar respecto de la última manifestación de la protección que el estatuto de los bienes familiares concede: el beneficio de excusión que pueden oponer ambos cónyuges a terceros acreedores del propietario. Este mecanismo apunta a defender la estabilidad familiar ya no frente a los actos del cónyuge propietario, sino frente a terceros -los acreedores de aquel-, de manera que se dirijan primeramente contra los restantes bienes del deudor, y solo a falta de estos puedan perseguir el bien declarado familiar como objeto del derecho de garantía general. Habida cuenta que los bienes familiares no tienen carácter inembargable ${ }^{14}$, se busca proteger a la familia ubicándolos en el último lugar de los bienes que pueden perseguir los acreedores en ejercicio de sus derechos. Y ello es demostrativo también de que la finalidad perseguida con la institución es una de contenido puramente familiar, de resguardo del lugar de desarrollo y convivencia de la familia, sin que cumpla otra función, como hemos planteado. Todas las consecuencias que derivan de la declaración de bien familiar apuntan a dicho objeto, quedando atrás una naturaleza netamente patrimonial de la figura.

La claridad respecto de la verdadera naturaleza y finalidad de los bienes familiares es fundamental para resolver acerca de la procedencia de su afectación como tales. Sus normas deben interpretarse en concordancia de estos fines al punto que constituyan la justificación última de la afectación. Por lo mismo, si no están presentes no cabe sino descartarla. Así, si se detecta que la solicitud de declaración busca una finalidad diversa a la descrita, el juez deberá, actuando dentro de sus facultades, rechazarla y negar lugar a ella. Como destaca Hübner, la expresión (empleada por el legislador) "podrán ser declarados familiares", confiere amplitud al juez para declararlos o no, de modo que "no obstante cumplirse los requisitos, el juez si estima que no se cumple la finalidad de la institución podría negar lugar a la solicitud" ${ }^{15}$.

Estas mismas consideraciones son las que pueden justificar la impugnación de la afectación como bienes familiares de los derechos sociales y acciones o su desafectación, como se verá en la sección que sigue.

\section{FinAlidAd Y ALCANCE DE LA AFECTACIÓN DE LOS DERECHOS Y ACCIONES SOCIALES DEL CÓNYUGE EN LA SOCIEDAD PROPIETARIA DEL INMUEBLE QUE SIRVE DE RESIDENCIA PRINCIPAL DE LA FAMILIA}

El precepto del artículo 146 del Código Civil da lugar al menos a dos problemas de innegable importancia práctica que, como se precisará, aparecen en el caso planteado

${ }^{14} \mathrm{La}$ inembargabilidad fue descartada fundamentalmente considerando que la mayor parte de las familias chilenas solo cuentan con un inmueble de su propiedad, siendo ese bien el de mayor trascendencia patrimonial, de modo que al ser declarado familiar, y con ello pasar también a ser inembargable, se afectaría considerablemente el acceso al crédito.

${ }^{15}$ Hübner, A. M., cit., p. 123. 
al inicio de este trabajo y cuya respuesta exige considerar, primeramente, la finalidad general de los bienes familiares a la que refiere la sección anterior; luego, es preciso examinar el tenor del precepto, fijando su verdadero sentido, y junto con ello, develar su fundamento y finalidad, estableciendo el genuino alcance de esta especial forma de afectación. Estos dos últimos tópicos, junto con la solución a los problemas, serán objeto de la presente sección.

\section{Sobre la afectación del artículo 146 del Código Civil y sus efectos}

El artículo 146 dispone:

"Lo previsto en este párrafo se aplica a los derechos o acciones que los cónyuges tengan en sociedades propietarias de un inmueble que sea residencia principal de la familia.

Producida la afectación de derechos y acciones, se requerirá asimismo la voluntad de ambos cónyuges para realizar cualquier acto como socio o accionista de la sociedad respectiva que tenga relación con el bien familiar.

La afectación de derechos se hará por declaración de cualquiera de los cónyuges contenida en escritura pública. En el caso de una sociedad de personas deberá anotarse al margen de la inscripción social respectiva, si la hubiere. Tratándose de sociedades anónimas se inscribirá en el registro de accionistas”.

Como se advierte, el precepto transcrito autoriza la declaración de bien familiar de los derechos y acciones de que sean titulares los cónyuges en la sociedad propietaria del inmueble que sirve de residencia principal a la familia. La norma tiene por objeto, como lo sostiene parte de la doctrina -así lo explicaremos-, la afectación de una especie de propiedad indirecta del cónyuge socio sobre el inmueble. Se interpone entre aquella y este, la sociedad, que es formalmente la propietaria. El cónyuge es titular-dueño- de derechos y acciones sociales en esa sociedad, no así, al menos directamente, de tal inmueble.

Es admisible poner de relieve la forma cómo se produce la afectación de los derechos y acciones sociales. Para ella es suficiente, según el inciso final del artículo 146, la declaración del otro cónyuge que conste por escritura pública, más la anotación marginal o inscripción en el registro respectivo, sin necesidad de intervención judicial ${ }^{16}$. Como lo explicaremos, ante esta forma de afectación al cónyuge titular solo le quedaría solicitar

${ }^{16}$ En el proyecto original la afectación de cualquier bien como familiar se producía por declaración solemne, sin intervención judicial. Sin embargo, durante la tramitación de la ley se incorporó la necesidad de que la afectación fuera judicial, quedando aislado, como una excepción, el supuesto del artículo 146 del Código Civil, sin advertir la razón de la diferencia. Para algunos autores, como Corral, ello se explicaría por una simple omisión de los legisladores, que cambiaron el procedimiento del artículo 141, pero se olvidaron de hacerlo con el artículo 146. Corral, H., cit., p. 77. 
ante el juez de familia la desafectación de los derechos y acciones sociales por no concurrir las condiciones que configuran el supuesto de la norma. Se produce la inversión de la carga de accionar a favor del cónyuge no socio, forzando al otro a recurrir a los tribunales, oponiéndose a la afectación realizada en la forma prevista por el legislador.

También, conviene precisar que la norma prevé la afectación como bien familiar de los derechos y acciones, no así del inmueble propiedad de la sociedad. Y lo decimos porque el inciso segundo da pie para entender que el bien familiar es el inmueble y no los derechos y acciones sociales, al referirse a él con dicha calificación ${ }^{17}$. Para develar el sentido de la norma, evitando esta errónea comprensión de su tenor, es fundamental volver a la idea de propiedad indirecta del inmueble que sirve de residencia de la familia. Como señalamos, entre el cónyuge socio y el inmueble se interpone formalmente quien aparece como dueña, la sociedad concernida.

Así, la aparente confusión a que induce la lectura literal de la norma se resuelve considerando la finalidad general de los bienes familiares examinada en la sección primera

${ }^{17}$ En la doctrina, destacando esta imprecisión y concluyendo que solo es posible entender que la expresión "bien familiar" quiere aludir al inmueble, no obstante no ser este el afectado, por todos: Corral, H., cit., pp. 81-82. Es preciso destacar que esta prevención no es irrelevante, desde que en la práctica la redacción de la norma ha ocasionado dificultades al confundirse la afectación de los derechos o acciones sociales con la del inmueble en cuestión. En tal sentido puede citarse un caso en que la Corte Suprema, en sentencia de 12 de septiembre de 2000, rechaza la casación deducida contra el fallo de la Corte de Apelaciones de Talca, confirmatorio de la sentencia de primera instancia, que niega lugar una solicitud de desafectación de bien familiar que incurre en un error a consecuencia del tenor literal del artículo 146. Se trataba de un matrimonio en que los cónyuges, siendo socios de una sociedad dueña de un predio en que se encuentra ubicada la residencia principal de la familia, proceden a afectar recíprocamente sus respectivos derechos sociales, de conformidad con el artículo 146 del Código Civil. Con posterioridad, el marido, actuando en su calidad de administrador de la sociedad, y afirmando la existencia de una subdivisión del predio de propiedad de la sociedad, interpone una demanda de desafectación de todos los lotes, salvo aquel en que se encuentra construido el inmueble familiar, fundado en que ellos no cumplen los fines previstos por el artículo 141, de modo que es procedente su desafectación, según lo dispone el artículo 145 del Código Civil. En la contestación, la cónyuge demandada se opone a la desafectación alegando que lo afectado son los derechos sociales, y no la propiedad, pues de esta es dueña la sociedad, dejando en evidencia la confusión de la parte demandante. Esto fue confirmado por el juez a quo, que señaló: "En el caso sub lite se encuentran afectados, como bien familiar, la calidad de las acciones y derechos sociales que corresponden al cónyuge en la Sociedad, habida consideración de ser ella actualmente la propietaria del inmueble denominado Parcela $n^{\circ} 57$ del proyecto de parcelación Los Cristales, en el cual se encuentra construida la casa habitación que sirve de residencia principal de la familia [...] teniendo en consideración que dicha afectación no recae precisamente sobre la propiedad de que es dueña la Sociedad Agrícola, sino que la afectación está referida solo al $5 \%$ de las acciones y derechos sociales que le corresponden al cónyuge en la referida sociedad [...] se concluye que resulta improcedente solicitar la desafectación de trece de los catorce lotes del predio materia de la controversia”. Ello es ratificado por el tribunal de alzada y la Corte Suprema, quedando así claro que no obstante la redacción del artículo 146 inciso segundo, el bien familiar lo constituyen los derechos y acciones y en ningún caso el inmueble mismo. En efecto, la Corte de Apelaciones acoge la argumentación de la demandada al expresar que "en el caso sub lite la afectación como bien familiar recayó sobre bienes incorporales (acciones y derechos) y que en el presente juicio se pretende la desafectación de una parte de un bien corporal (13 de 14 lotes particularizados en un plano) lo que no resulta procedente de modo alguno". Asimismo se deja de manifiesto que la sociedad carece de legitimación para demandar la desafectación y que es el cónyuge quien debe actuar en su calidad de tal, y no como administrador de la misma, que era la forma en que había ejercido la acción. Sentencia disponible en www.legalpublhing3.cl identificador CL/JUR/2143/2000. 
de este trabajo. En efecto, por medio de la afectación de los derechos y acciones sociales se alcanza la finalidad de protección de la familia y la continuidad de la residencia de la misma pese a la ruptura matrimonial. Por esta vía, el legislador asegura, incluso en estas hipótesis de propiedad indirecta, la consecución de los fines generales de los bienes familiares. Volveremos acerca de este punto al precisar el fundamento y finalidad particular de la afectación del artículo 146 del Código Civil.

En lo que concierne a los efectos de la declaración de los derechos y acciones sociales como bienes familiares, estos son de dos clases, los particulares del artículo 146 y los generales de la afectación como bien familiar, previstos por el artículo 142, ambos del Código Civil. El efecto particular se traduce en la exigencia de contar con la voluntad de ambos cónyuges para realizar cualquier acto como socio o accionista de la sociedad respectiva que tenga relación con el inmueble. El problema a que da lugar esta restricción, atendida la redacción de la norma, refiere a cuáles actos sociales requieren de la intervención del cónyuge no propietario. Este problema es uno de los que anticipamos y que abordaremos más adelante.

Asimismo, llama la atención que el legislador para esta clase de bienes familiares prevea como restricción para ciertos actos la necesidad de la voluntad del cónyuge no propietario y no su autorización, como sí lo hace el artículo 142 del Código Civil. Fuera de no existir armonía entre las dos disposiciones, sin haber justificación alguna, el uso de esta expresión es inconveniente al no ser el cónyuge no propietario titular de los derechos o acciones sociales.

Además de esta limitación debe considerarse que pese a la letra del precepto -que da pie para entender que el único efecto de esta especial afectación es el arriba expuestohay acuerdo en orden a que también serían aplicables los efectos generales de los bienes familiares conforme con el citado artículo 142, de tal forma que el cónyuge titular de los derechos y acciones quedaría no solo sujeto a la limitación del artículo 146, sino también a las restricciones que el primero establece, no respecto de la disposición del inmueble, sino de los derechos y acciones sociales objeto de afectación, en el sentido que no podrá enajenar o gravar voluntariamente sus derechos o acciones sociales, ni prometer su gravamen o enajenación sin la autorización del cónyuge no propietario ${ }^{18}$.

Entender las cosas de otra forma, implicaría dejar abierta la posibilidad de burlar la finalidad de la institución, perjudicando el interés familiar que se busca proteger. En efecto, de no someterse al cónyuge titular a esta restricción, sería suficiente enajenar o prometer enajenar tales derechos y acciones, desprendiéndose de su calidad de socio, frustrando aquello que persigue esta especial afectación.

En síntesis, debemos entender que con el objeto de asegurar la consecución de la finalidad general de los bienes familiares, el cónyuge titular de los derechos o acciones queda sujeto a dos limitaciones: la primera que dice relación con actos sociales que incidan en el inmueble residencia principal de la familia; y la segunda, consistente

${ }^{18}$ Así se pronuncia Corral, H., cit., p. 81, quien al referirse a los efectos de la declaración de bien familiar respecto de los derechos y acciones, expresa que a estos, "además de los anteriores" (que corresponden a los del artículo 142), se aplica lo previsto en el artículo 146 del CC. 
en los efectos generales del artículo 142, respecto del objeto afectado, los derechos y acciones sociales ${ }^{19}$.

\section{Dos problemas a que da lugar la regla del artículo 146 del Código Civil: su solución a partir de su fundamento y finalidad}

Como anticipamos al inicio de esta sección, la norma del artículo 146 del Código Civil plantea dos problemas cuya solución resulta necesaria para su acertada comprensión y aplicación. El primero: ¿a qué clase de sociedades aplica la afectación de los derechos o acciones? Si bien de la letra de la ley parece que cabría la afectación cualquiera fuera la clase de sociedad, entendemos, sin embargo, que existen buenas razones para restringir su alcance. Y el segundo, que ya adelantamos, ¿qué actos del cónyuge ejecutados en su calidad de socio o accionista quedan sometidos a la limitación del artículo 146? Al igual que respecto del problema anterior, debido a la amplitud del precepto, pareciera que la norma alcanzaría a toda clase de actos, empero pensamos que solo afectaría a algunos.

La respuesta a estas dos cuestiones requiere examinar previamente el fundamento y finalidad particular de la regla de afectación de los derechos o acciones sociales, en conexión con aquella que en general subyace a la institución de los bienes familiares.

a) Cuestión previa. Fundamento y finalidad particular de la afectación de los derechos y acciones sociales como bienes familiares.

A partir del antecedente de la propuesta de Barros y considerando la norma finalmente incorporada al proyecto del gobierno que fuera aprobada como ley, se infiere que si bien el objeto directo de la declaración como bienes familiares lo constituyen los derechos y acciones sociales, tal afectación apunta a conferir indirecta, pero efectivamente, protección a la familia en relación con el inmueble en que vive. La afectación de estos derechos o acciones solo se justifica en miras al aseguramiento de la residencia de la familia en el inmueble de propiedad de la sociedad, razón por la que debemos coincidir en que la finalidad perseguida con esta declaración no consiste en retener tales derechos y acciones en el patrimonio de su titular, sino en la protección de la familia, asegurándole su lugar de habitación o residencia ${ }^{20}$. En otros términos, la titularidad de tales derechos y acciones resultaría indiferente para los efectos de esta institución si la sociedad en que recaen no fuere propietaria del inmueble que sirve de residencia a la familia. Lo que explica esta regla es precisamente esta última circunstancia, y es la que justifica que se hable de la afectación de una propiedad indirecta, al interponerse entre el inmueble y el

${ }^{19}$ Rosso, cit., p. 205. El autor expresa que la limitación en este caso "opera en una doble dimensión: por una parte, respecto de los actos celebrados sobre los derechos o acciones; y por otra, los actos que como socio o accionista puede realizar el cónyuge titular en relación al inmueble familiar".

${ }^{20}$ Cfr. Rosso, cit., p. 113. El autor expresa que los derechos y acciones en sociedades como objeto de declaración familiar tienen un carácter directo, pero como objeto de protección, tiene un carácter indirecto, ello, porque lo protegido es la permanencia de la familia en su residencia. 
cónyuge socio -y por consiguiente, la familia que reside en ella- la sociedad. Entonces, la regla especial del artículo 146 es en definitiva manifestación de la finalidad general perseguida por los bienes familiares según lo expresado en la primera sección de este trabajo. Así lo confirma además el examen de la historia del establecimiento de la ley y los antecedentes previos a la iniciativa legislativa en el Poder Ejecutivo.

En efecto, la propuesta del profesor Barros, en la que se inspiró el proyecto de ley, lo que sugiere es extender el carácter de bien familiar a aquellos bienes de propiedad indirecta de uno de los cónyuges, como cuando pertenezcan a una sociedad cuyo interés mayoritario corresponda a dicho cónyuge ${ }^{21}$. No obstante la amplitud de la regla propuesta por Barros, al referirse en general a los bienes de propiedad indirecta, ofreciendo simplemente como ejemplo el caso de la sociedad, el Mensaje del Ejecutivo incluyó la norma refiriéndola solo a los derechos y acciones sociales en sociedades propietarias de inmuebles en los que tuviera la residencia principal la familia. Y así se aprobó la disposición del artículo 146 del Código Civil. La discusión parlamentaria se centró precisamente en que por este medio era posible proteger el interés familiar cuando el inmueble fuere de propiedad de una sociedad y que de no contemplarse tal supuesto no sería posible alcanzar tal protección ${ }^{22}$. De esta forma, debe concluirse que esta regla busca extender el ámbito de protección de los bienes familiares al alcanzar a aquellos inmuebles respecto de los cuales uno de los cónyuges detenta esta suerte de propiedad indirecta. Como afirma Corral, esta afectación "pretende evitar que por medio de una propiedad indirecta, a través de formas societarias (bastante comunes en los últimos años en los que han proliferado entre cónyuges), se eluda el estatuto de los bienes familiares" 23 . Con una opinión similar, Rodríguez Grez, al referirse a esta forma de afectación y sus efectos, sostiene que al parecer la intención de la ley estaría encaminada a regular lo que sucede con lo que él llama sociedades "familiares" en el que uno o ambos cónyuges detentan gran parte o la totalidad del interés social ${ }^{24}$.

En este contexto, la pregunta que surge es: ¿qué efecto se seguiría de no existir la norma del artículo 146 del Código Civil? Aunque no aparece explícitamente en la discusión parlamentaria, la respuesta es sencilla, al cónyuge propietario del inmueble en que reside la familia le sería bastante sencillo burlar la finalidad de protección del interés familiar que busca la institución y, así, sustraer tal inmueble, aportándolo a una sociedad o creando una de papel, y enajenándolo luego mediante ella, perjudicando el

${ }^{21}$ Se trata del inciso segundo del artículo 1720 propuesto por Barros, E., cit., p. 133.

${ }^{22}$ Como consta en la Historia del establecimiento de la Ley $N^{0} 19.335$, p. 304, disponible en www.bcn. cl, durante la discusión en la Comisión de Constitución, Legislación, Justicia y Reglamento del Senado, se analizaron las opciones existentes para solucionar la aplicación de la calidad de bien familiar respecto de estos bienes, que pertenecen a una persona jurídica distinta de los cónyuges, en la que estos tienen solamente derechos, por medio de las acciones. La conclusión fue dar la calidad de familiares a los derechos sociales como lo planteaba el inciso primero del artículo propuesto.

${ }^{23}$ Corral, H., cit., p. 67.

${ }^{24}$ Rodríguez, P., Regímenes patrimoniales, Editorial Jurídica de Chile, Santiago, 1996, p. 293. 
interés objeto de protección. En tal sentido se pronuncia Court ${ }^{25}$. Ello es precisamente lo que se busca evitar con esta especial categoría de bienes susceptibles de declararse como familiares.

En síntesis, debe concluirse que la finalidad particular de la afectación de los derechos y acciones sociales como bienes familiares es la concreción del fin general de la institución, a saber, el resguardo de la familia y su lugar de residencia. Es ese el interés protegido y en función de él deberá interpretarse y aplicarse el artículo 146 del CC. Por tal razón, si una afectación de este tipo aparece fundada exclusivamente en provecho individual del cónyuge que la realiza y no en el interés familiar, debe calificarse como improcedente, y el cónyuge socio cuya participación social fue afectada puede instar judicialmente por la desafectación.

\section{b) Los problemas}

\section{i) ¿A qué sociedades se aplica la norma?}

La primera cuestión que surge, como adelantamos, refiere a si la disposición y limitaciones que ella impone son efectivamente susceptibles de aplicarse a cualquier sociedad propietaria de un inmueble que sirva de residencia principal a la familia y en la que al menos uno de los cónyuges tuviere la calidad de socio o accionista, o si por el contrario, es preciso restringir su ámbito de aplicación solo a ciertas sociedades, bajo determinados criterios que habrán de establecerse. La solución a la que arribemos acarrea consecuencias importantes, desde que repercutirá en su aplicación en el terreno práctico, y más precisamente, será determinante en la solución de los conflictos a que dé lugar esta clase de afectación.

Si bien es indudable que la norma no formula distinción alguna, de manera que hay razones para aceptar y adherir a una interpretación en tal sentido, estimamos que existen también buenos argumentos para sostener que no es posible entenderla en este sentido. En primer lugar, una comprensión amplia del precepto podría dar lugar a situaciones de perjuicio para los restantes socios o accionistas, terceros ajenos a la relación familiar. Pensemos, por ejemplo, en una sociedad donde uno de los socios haya visto afectados como familiares sus derechos y acciones, sin tener calidad de mayoritario. Si la sociedad requiere acceder a créditos para su funcionamiento y el banco exige una hipoteca sobre el inmueble concernido -residencia de la familia- y al ser requerida la voluntad del cónyuge no titular, este se niegue a otorgarla, se impediría la concreción de la operación bancaria y del negocio social. En la lectura amplia del precepto no habría forma de eludir ni la afectación ni la paralización de tal negocio, sin embargo parece ser de sentido común que una solución como esta no se aviene con la finalidad de los bienes familiares, dejando abierta la posibilidad de abuso por el cónyuge no socio, afectándose a terceros ajenos y

25 Court, E., Los Bienes Familiares en el Código Civil (Ley $N^{\circ} 19.335$ ), Cuadernos Jurídicos, $\mathrm{N}^{\circ} 2$, Universidad Adolfo Ibáñez, Viña del Mar, 1995, p. 43. 
al tráfico jurídico. En efecto, la negativa del cónyuge no titular impediría la realización del referido negocio aunque el interés social del otro cónyuge fuera minoritario; o pese a que la Junta de Accionistas por mayoría de las acciones aprobara el endeudamiento y constitución de la garantía real.

El ejemplo propuesto nos muestra la necesidad de restringir las sociedades en las que puede tener aplicación esta forma de afectación. Queda en evidencia que no puede ser cualquiera. Entonces, la cuestión que subsiste es ¿Cuáles son aquellas en que sí procede aplicar el artículo 146 del CC? Es lo que trataremos de dilucidar a continuación.

Es posible hacer presente que en la idea de delimitar el alcance del precepto en estudio, se ha planteado que podría incluso discutirse la posibilidad de afectación de derechos o acciones que pertenezcan exclusivamente a uno de los cónyuges, ya que el artículo 146 se expresa en términos de derechos y acciones que tengan "los cónyuges" 26 . Tal redacción conduciría a entender que solo sería procedente esta forma de afectación en sociedades en las que ambos cónyuges sean titulares en común de derechos o acciones, restringiendo notoriamente su alcance y sin más sustento que la literalidad del precepto. También apoyándonos en su letra, podríamos entender que se aplica exclusivamente a sociedades en que ambos cónyuges, por separado, tengan la calidad de socios o accionistas. Esta lectura, aunque resulta más acorde con lo que se observa en la práctica, igualmente nos lleva a una excesiva e injustificada limitación de su aplicación, al no concordar con el fundamento y finalidad de esta afectación. No debemos olvidar que la propuesta original, anterior al proyecto del ejecutivo, ponía el acento en la propiedad indirecta existente sobre el inmueble, alcanzando incluso a las comunidades en las que uno de los cónyuges era partícipe. Teniendo en cuenta que el ejecutivo circunscribió la norma a la participación en sociedades, podemos coincidir en que si bien su aplicación es limitada, ella debería extenderse a todas aquellas hipótesis en que suprimiendo la sociedad propietaria, aparecería como verdadero dueño el cónyuge socio o accionista. Debemos asignar al precepto un sentido que permita evitar que con la constitución de sociedades se eluda la aplicación de los bienes familiares. De ahí que la norma deba interpretarse y aplicarse restrictivamente, pero sin incurrir en excesos que impidan la consecución de tal finalidad.

Por esta razón entendemos que para definir en qué sociedades procede la afectación de los derechos y acciones es necesario considerar diversos criterios, que permitan concluir - del modo más inequívoco posible- que se trata de una sociedad que detenta la propiedad indirecta del inmueble residencia de la familia en los términos explicados, resguardando, en su justa medida, la finalidad de la que hemos venido hablando. Entre tales criterios, estimamos pertinentes los que siguen:

Primeramente, la circunstancia que uno de los cónyuges sea titular de un interés mayoritario en la sociedad propietaria. Ello nos muestra el caso más evidente, aunque no concluyente necesariamente, de propiedad indirecta. En efecto, no es extraño que el cónyuge propietario del inmueble residencia de la familia constituya una sociedad

\footnotetext{
${ }^{26}$ Corral, H., cit., pp. 67 y 68.
} 
aportándolo. Si bien las motivaciones del aporte pueden ser de diversa naturaleza, a los efectos que nos interesa, la consecuencia que se seguiría de no haberse previsto la afectación del artículo 146, sería la sustracción de este inmueble de la protección de los bienes familiares, pudiendo verse afectado el interés de la familia. De la historia del establecimiento de la ley se infiere que si bien los legisladores tuvieron en mente este supuesto, no podemos excluir a priori otros casos, justificándose así la inclusión de otros criterios que contribuyan a la convicción judicial de estar ante una propiedad indirecta del inmueble familiar.

Seguidamente, que la sociedad pueda considerarse como familiar. Estaremos ante una de tal naturaleza cuando esté conformada por ambos cónyuges, o por uno de ellos y otros familiares. Sin embargo, para los efectos que aquí interesan no basta tal calificación, sino que se requeriría, además, que el cónyuge titular de los derechos y acciones que se pretenden afectar disponga de facultades de disposición, cuyo ejercicio ponga en riesgo la titularidad social del inmueble que sirve de residencia a la familia. Igualmente, aunque la sociedad no sea de carácter familiar, si concurre esta última circunstancia -unida a la anterior o a otras de las que se mencionan a continuación- podríamos estimar procedente la afectación en estudio.

En tercer lugar, la realidad del objeto social. Entendemos que el objeto de la sociedad no tendría realidad cuando esta aparezca como mero instrumento justificativo de la titularidad del inmueble, que constituye su único o principal activo patrimonial. Si este es el caso, tendríamos claras razones para incluir a esta sociedad en el ámbito de la norma de interés.

Finalmente, debemos atender a si la limitación que envuelve la afectación del artículo 146 CC pone en riesgo o afecta el interés o derechos de terceros. Quiere decir que aunque el cónyuge sea titular de un porcentaje mayoritario y detente facultades de disposición, si se constata la realidad del objeto -descartando la idea del sociedad instrumento o de papel-y las limitaciones del estatuto de los bienes familiares impiden la realización de tal objeto, perjudicando el interés o derechos de los otros socios o accionistas, no procedería esta particular afectación.

Según sea el caso concreto, el juez deberá acudir a estos criterios y otros que estime pertinentes en vistas a los fines de la afectación, ponderándolos en su conjunto, para así resolver acertadamente sobre la impugnación o solicitud de desafectación de los derechos o acciones.

A partir de lo expresado, y volviendo al caso planteado al inicio de este trabajo, podemos decir que en un supuesto como el descrito no sería procedente la afectación de las acciones del marido como bien familiar al no tratarse de una sociedad que quede comprendida en su ámbito de aplicación. Concretamente, no estamos ante una sociedad que ostente la propiedad indirecta de inmueble en cuestión. Arribamos a tal solución aplicando los criterios propuestos previamente. En efecto, el marido no tiene una participación mayoritaria. Tampoco se trata de una sociedad familiar, en tanto los restantes socios son terceros. Adicionalmente, el giro de la sociedad es real y efectivo, dedicándose a las inversiones de diverso tipo, y por tanto una afectación de las acciones del marido podría incidir en los intereses de los restantes accionistas. Un dato relevante 
además para tener en consideración, es que el inmueble fue adquirido por la sociedad con bastante antelación a la celebración del matrimonio del cónyuge accionista, todo ello no hace sino que distanciarla del sentido original de esta forma de afectación y, por consiguiente, del supuesto de procedencia de la norma.

\section{ii) ¿Qué actos quedan sujetos a la limitación del artículo 146 CC?}

El tenor literal del precepto plantea una segunda interrogante: ¿efectivamente la restricción de contar con la voluntad del otro cónyuge se aplica a cualquier clase de acto realizado como socio o accionista? o bien ¿conforme la finalidad general de los bienes familiares, y la particular que explica esta forma de afectación, debiera limitarse su alcance solo aquellos que pongan en riesgo su consecución? ${ }^{27}$

La respuesta a estas interrogantes plantea primeramente la cuestión acerca del alcance que debe asignarse a la expresión del precepto "cualquier acto como socio o accionista de la sociedad respectiva" y que refiere a la calidad en la que el cónyuge ejecuta o celebra el acto concernido. En la doctrina, Corral $^{28}$ advierte que esta regla puede dar lugar a dificultades y que le parece que quedarían excluidos los casos en que el cónyuge socio actúa no como tal sino como administrador de una sociedad de responsabilidad limitada, y que en uso de sus facultades enajena o da en arrendamiento el inmueble que sirva de residencia principal de la familia. Por su parte, Rosso ${ }^{29}$ categóricamente afirma que quedan excluidos de la norma aquellos actos efectuados como gerente, director, presidente, administrador, mandatarios y otros de similares características, afirmando que los actos que necesitan de la intervención del otro cónyuge son lo que realiza el titular en su calidad de socio o accionista. No coincidimos con esta interpretación que si bien se apega al tenor literal de la norma, al mismo tiempo toma distancia de la finalidad que persigue el legislador al establecer esta particular forma de afectación, la que es determinante para fijar el alcance de la norma. En efecto, cómo podríamos justificar que el cónyuge socio o accionista no queda sujeto a la limitación de la norma por el solo hecho de obrar en calidad de administrador de la sociedad, sobre todo cuando el caso más usual en la práctica -y que precisamente se representó el legislador- es el de las sociedades de personas en las que el cónyuge titular detenta amplias facultades de administración. Adherir a esta interpretación restrictiva implicaría sencillamente reducir en extremo el alcance de la norma. No debemos olvidar que un socio o accionista por sí carece de facultades de administración y disposición de bienes sociales, salvo

${ }^{27}$ Rosso se encarga de poner de relieve esta interrogante cuando expresa que la disposición "no se preocupa de individualizar, a lo menos de un modo general (como lo hace el artículo 142), los actos que como socio o accionista no puede realizar el cónyuge titular la autorización de su marido o mujer". Plantea asimismo que del tenor de la norma parece que el legislador intentara abarcar la mayor cantidad de actos posibles, lo que en su opinión llamaría la atención, considerando que el alcance de la limitación tratándose del artículo 142 es más restringido. Rosso, cit., p. 207.

\footnotetext{
${ }^{28}$ Corral, H., cit., p. 82.

${ }^{29}$ Rosso, cit., p. 207.
} 
la participación que podría caberle en aquellas sociedades en que se requiere de la intervención de los accionistas para ciertos actos de disposición, como es el caso de las sociedades anónimas y podría serlo el de las sociedades por acciones. A nuestro modo de ver, el criterio para definir si el acto está o no comprendido en la norma no refiere a la calidad en que actúa el cónyuge socio o accionista sino si se pone o no en riesgo la finalidad de esta afectación. Así lo explicaremos a continuación.

Si nos quedamos con la letra del artículo concluiríamos que la limitación comprendería todos aquellos actos que incidan - de cualquier modo- sobre el inmueble de propiedad de la sociedad y que sirve de residencia familiar. La ley no formula distingo alguno, he ahí esta primera aproximación. Sin embargo, entendemos que tal lectura debe descartarse, y que debemos optar por una interpretación armónica con el artículo 142 del Código Civil, que establece la regla general en lo que concierne a las limitaciones que emanan de la afectación como bien familiar, y que, como sabemos, refieren solamente a aquellos actos jurídicos que puedan privar al o los beneficiarios del uso y goce del inmueble, o bien ponerlo en riesgo ${ }^{30}$. No se divisa justificación alguna que explique una diferencia de trato entre los derechos y acciones sociales declarados familiares, y los otros bienes que pueden ser objeto de tal declaración, conforme al artículo 141 del Código Civil.

Sostener que todo acto social vinculado con el inmueble se ve alcanzado por las limitaciones, conduciría a una extensión injustificada de la aplicación de la norma y de los efectos de los bienes familiares, al punto de poder entrabar el funcionamiento de la sociedad. Representémonos un caso para ilustrar lo expresado:

Uno de los cónyuges tiene participación en una sociedad del giro inmobiliario y que es dueña de un predio objeto de una subdivisión, con el fin de proceder a la venta posterior de los lotes como parcelas de agrado. Y en uno de ellos la sociedad construye una vivienda que sirve de residencia principal a la familia del socio aludido. Si aplicamos literalmente el precepto en estudio, mediando la afectación de los derechos sociales del cónyuge partícipe, este -y la sociedad en último término- requeriría de la voluntad del cónyuge no socio para la enajenación de cualquiera de los restantes lotes. En cambio, si hacemos un esfuerzo por develar el verdadero sentido y alcance de la norma, que armonice con la finalidad de los bienes familiares y que concilie los intereses en juego, deberíamos preguntarnos ¿cuáles actos o a qué actos refiere la limitación de la voluntad del cónyuge no socio? 31

${ }^{30}$ Eso es lo que se puede concluir de la revisión de los actos enumerados en la norma, y sin perjuicio de lo ya indicado en el sentido de que la sola declaración de bien familiar no asegura el uso y goce efectivo, y que por ello se prevé la posibilidad de constitución de los derechos reales de usufructo, uso y habitación. En rigor, el artículo 142 contempla los actos que impedirían o pondrían en riesgo que pudiera mantenerse la residencia familiar en el inmueble en cuestión. En igual sentido, Rosso, cit., p. 207.

${ }^{31}$ En relación con el supuesto hipotético aquí propuesto, debemos destacar que se acerca -y perfectamente pudo haberse planteado en tal caso- a aquel que motivó el fallo de la Corte Suprema de 12 de septiembre de 2000, al que se hizo referencia en la nota 17: el marido, demandante en representación de la sociedad, precisamente alegaba que el predio en que estaba construido el inmueble residencia de la familia se encontraba subdividido en varios lotes, y solamente en uno de ellos debía mantenerse la afectación como bien familiar, por ser aquel donde estaba la vivienda familiar. Como comentamos en su momento, la demanda no estaba 
De lo que se trata es de determinar si todo acto social o solo alguno requeriría de tal voluntad. Si el criterio decidor es la finalidad general de los bienes familiares y aquella particular del artículo 146, todo pareciera indicar que tal voluntad solo sería necesaria si el acto de enajenación recayere en el lote en el que se halla la vivienda familiar. De extenderse a los restantes no solo se desviaría la finalidad aludida, sino que también se lesionaría sensiblemente la ejecución del objeto social, a saber, la venta de los restantes lotes, inocuos para la protección de la familia. Partiendo de la base que se trata de una sociedad propietaria indirecta del inmueble residencia principal de la familia, igualmente hace falta introducir alguna clase de restricción, que tomando como prevalente el interés y protección de aquella, no llegue a desatender la circunstancia que aún en estos casos tales sociedades igualmente pueden poseer un objeto real. De este modo, en caso de producirse una tensión entre el interés familiar y la realidad del objeto, ella se resolverá a favor del primero; sin embargo, de estar ausente dicha oposición -cuestión que tendrá que definir el juez que conozca del asunto- no es admisible una extensión de la norma que responda a una aplicación literal acrítica del precepto. En casos como estos el remedio sería peor que la enfermedad.

Volviendo al caso, la tensión a la que aludimos se daría en el evento que el marido tratara de enajenar el lote residencia de la familia, considerando que realmente la sociedad tiene por objeto el negocio inmobiliario. De ser así, sería necesaria para dicho acto de enajenación la voluntad de su cónyuge. Yendo al otro extremo, pensando en el supuesto original, no se presentaría la tensión, de modo que prevalecería la realidad del objeto y sería improcedente la exigencia de voluntad.

En consecuencia, entendemos que la norma referiría solo a actos jurídicos de enajenación en sentido amplio y de cesión de derechos de uso y goce de la tenencia del inmueble de propiedad de la sociedad, en la medida que su realización afecte o perjudique la, tantas veces aludida, finalidad de los bienes familiares ${ }^{32}$. Por consiguiente, el fin de

bien deducida por cuanto se pedía desafectar los restantes lotes, en circunstancias que lo declarado familiar eran los derechos sociales del marido, y no el predio; y porque además quien debía demandar era este y no la sociedad, como ocurrió en tal caso. No obstante que no se probó en dicho supuesto tampoco la efectiva subdivisión del predio, de haber sido real, lo planteado aquí podría haber tenido lugar si en vez de pedirse la desafectación de la forma en que se hizo, se hubiera procedido a la enajenación de aquellos lotes en que no se encontraba ubicado el inmueble de la familia. En tal caso podría haberse presentado la dificultad de resolver si para dichas enajenaciones debía contarse con la voluntad de la cónyuge que había procedido a la afectación, y según lo que sostenemos, la respuesta tendría que haber sido negativa, por no ajustarse a los fines perseguidos con la afectación.

${ }^{32}$ En tal sentido, conviene tener en cuenta lo destacado por Fabiola Lathrop, refiriéndose al proyecto de ley encaminado a modificar la regulación de los sistemas de bienes del matrimonio, que en materia de bienes familiares, y más concretamente, en lo que concierne a los alcances de la afectación de derechos y acciones sociales, pretende precisar, como destaca la autora, "la interpretación de la actual frase del artículo 146 inciso segundo [...] ya que, hoy en día, las palabras cualquier acto dificultan la determinación de los actos que se refieren al inmueble y que son realizados por uno de los cónyuges como socio o accionista. En efecto, el Proyecto agrega que este acto debe significar la enajenación, gravamen o cesión de la tenencia del inmueble que sirva de residencia principal de la familia o de los muebles que la guarnecen" (lo destacado es de la autora). Lathrop, F. Bienes familiares, situación actual y derecho proyectado, Colegio de 
la regla del artículo 146 se entendería satisfecho restringiéndola a los actos aludidos que recaigan en el inmueble social, sin extenderla a otra clase de actos que no tengan incidencia en la conservación y permanencia de la residencia familiar.

Finalmente, si volvemos al caso inicialmente presentado, la respuesta acerca de si procede o no aplicar la limitación del artículo 146 CC es negativa, no porque atendamos al acto o a su naturaleza sino porque, como se ha dicho, la afectación se excluiría considerando la sociedad de que se trata. Sin embargo, para completar este ejercicio, pensemos en el siguiente supuesto en el que sí procedería la afectación de las acciones. El inmueble en el que reside la familia es uno de mayor extensión y en él operan parte de las oficinas de la sociedad de que es socio el cónyuge. Pues bien, se decide subarrendar parte del inmueble -que admite división sin detrimento de la vivienda familiar- para efectos tributarios de gran impacto en la contabilidad de la sociedad. La aplicación literal del precepto nos indica que tal acto no puede celebrarse sin la voluntad del otro cónyuge, en cambio la que aquí se propone admitiría el acto sin exigencia alguna ${ }^{33}$.

\section{Conclusiones}

1. La afectación del artículo 146 CC como bien familiar de los derechos sociales o acciones en sociedades propietarias del inmueble que sirve de residencia principal de la familia debe interpretarse a la luz del fundamento u finalidad general de los bienes familiares y sin desatender a lo que el legislador busca proteger especialmente con la regla del citado precepto.

2. La norma persigue la protección de la residencia de la familia en aquellos casos en que por la constitución de una sociedad o tipo social se configura lo que hemos venido en denominar "propiedad indirecta" del inmueble en el que reside la familia.

3. Dos son los problemas que plantea la aplicación de la norma cuyas respuestas acarrea importantes consecuencias en el terreno práctico. La primera: ¿a qué sociedades aplica la norma? En nuestra opinión solo aquellas en las que es evidente que entre el

\footnotetext{
Abogados de Chile A.G., Santiago, 2008, p. 3-4. Como se aprecia, se trata, como aquí proponemos, de lograr concordancia entre los artículos 146 y 142 del CC.

${ }^{33}$ De cualquier modo, si estamos al caso planteado inicialmente, debemos poner de relieve que, cualquiera sea la razón para excluir la aplicación de la norma conforme al sentido que le hemos asignado, no podemos dejar de considerar que en dicho caso la cónyuge, al proceder a la afectación, hace un uso indebido o abusa de la facultad que le confiere la ley, toda vez que, según lo expresamos, el primer límite a que se sujetan los bienes familiares concierne al ejercicio abusivo del derecho y lo será, entre otras hipótesis, cuando quien intente el recurso a esta institución lo haga motivado en interés propio para la obtención de un provecho personal sin atender a la familia y su protección. Es importante hacer presente en esta línea, que en diversas sentencias referidas a solicitud de afectación como bien familiar, los tribunales han fallado destacando la importancia de que no se trate de obtener beneficios personales abusando de la institución. A modo de ejemplo: Sentencia Corte Suprema, 10 de agosto de 1998, Revisa Fallos del mes No 477, pp. 1415 y ss; Sentencia Corte de Apelaciones de Santiago, 24 de marzo de 1998, RDJ tomo 95, sección segunda, pp. 26 y ss; Sentencia Corte de Apelaciones de Santiago, 10 de octubre de 2001, disponible en www.legapublishing3. cl, identificador CL/JUR/384/2001; 21362
} 
inmueble y el cónyuge socio se interponga la sociedad con propietaria, en términos que de no existir la norma del artículo 146 CC el interés de la familia en la conservación de la residencia podría verse afectado. La segunda: ¿a qué actos o contratos alcanza la limitación prevista por el artículo 146 CC? Solo a aquellos en que, nuevamente, se puede ver afectada la permanencia de la residencia familiar y no otros.

4. Se demuestra en este trabajo que una aplicación literal del precepto lleva a excesos que no se condicen con el fundamento y finalidad general y particular de esta clase de afectación, ofreciendo argumentos de fuerza para impugnar la afectación o solicitar la desafectación de los derechos sociales o acciones.

5. Finalmente, el juez debe rechazar todo supuesto en el que aparezca evidentemente que el fin que se persigue con la afectación no es el resguardo de la residencia familiar, sino el interés propio del cónyuge que afecta unilateralmente y el subsecuente provecho personal.

\section{BIBLIOGRAFÍA}

BArros, E., "Proyecto para introducir en Chile la participación en los gananciales como régimen de bienes normal de matrimonio", en Merino, F. (coord.) Familia y Persona, Editorial Jurídica de Chile, Santiago, 1991.

Corral, H., Bienes familiares y participación en los gananciales: la reforma de la Ley $\mathrm{N}^{\circ} 19.335$, de 1994, a las relaciones personales y al régimen económico del matrimonio, Editorial Jurídica de Chile, Santiago, 2007.

Court, E., Los Bienes Familiares en el Código Civil (Ley 19.335), Cuadernos Jurídicos, N² 2, Universidad Adolfo Ibáñez, Viña del Mar, 1995.

Frigerio, C., Regimenes matrimoniales, Editorial Jurídica Conosur, Santiago, 1995.

Hübner, A.M., Los bienes familiares en la legislación chilena. Problemas y atisbos de solución, en Cuadernos de Extensión Universidad de los Andes, número 2, Santiago, 1998.

Lathrop, F., Bienes familiares, situación actual y derecho proyectado, Colegio de Abogados de Chile A.G., Santiago, 2008

Ramos, R., Derecho de Familia, tomo I, Editorial Jurídica de Chile, Santiago, 2010.

Rodríguez, P., Regimenes patrimoniales, Editorial Jurídica de Chile, Santiago, 1996.

Rosso, G.F., Régimen Jurídico de los Bienes Familiares, Metropolitana Ediciones, Santiago, 1998.

SCHмidt, C., Nuevo régimen matrimonial. Ley 19335 analizada y comentada, Jurídica Conosur, Santiago, 1995.

Tomasello, L., El régimen de participación en los gananciales, la reforma de la ley 19.335, Edeval ediciones, 1994. 